\title{
18. THE SULPHIDES OF CERTAIN DEEP-SEA SEDIMENT SAMPLES COLLECTED ON DSDP LEG 31
}

\author{
K. F. G. Hosking, University of Malayia, Kuala Lumpur, Malaysia
}

\begin{abstract}
The manner of occurrence of sulphides (pyrite and pyrite melnikovite?) in a number of samples from the Philippine Sea is described and their genesis briefly discussed.

Polished sections of consolidated material revealed both shards of volcanic glass and pyritized remains of microorganisms (Radiolaria?) in a pyrite matrix with a mosaic texture. The mosaic texture is thought to be due to early syneresis cracks and to late fracture during compaction.

Some shards are partly or completely replaced by small units of commonly well-ordered, brownish pyrite. In addition, the shards often display essentially transverse, pyrite-filled fractures that are thought to have been due to tension that built up as the sulphide matrix changed from a gel state to a crystalline one.

Sulphidization of the shards and microorganisms was followed by the development of the matrix pyrite and the pyrite occupying the fractures in the glass.

Some sulphide spherulites, with a crude radial texture, and a few sulphide cylinders (portion of the spines of sea-urchins?) were mounted in cells on microscope slides and superficially examined. No pyrite framboids occur in the material examined.

It is concluded that the sulphides were deposited at or near the water/sediment interface in an area of restricted circulation. It is considered that either the $\mathrm{H}_{2} \mathrm{~S}$ and any elemental sulphur necessary for their syntheses was derived from seawater sulphate $\left(\mathrm{SO}_{4}^{--}\right)$by biogenic processes. The source of the iron may have been hydrated iron oxide or the iron components may have originated at an unknown depth in the bedrock and subsequently migrated to the site of sulphide deposition.
\end{abstract}

\section{INTRODUCTION}

About 12 deep-sea sediments, collected during DSDP Leg 31, were made available to the writer for a study of their sulphide content. Of these, two provided data of considerable interest in that they were unusually rich in sulphides and sufficiently coherent for polished sections to be prepared from them. Two further samples of sulphide material previously sealed in cells on microscope slides provided some further information of interest.

\section{DESCRIPTIONS OF THE POLISHED SECTIONS}

\section{Sample 1 (31-297-25-1, $47 \mathrm{~cm})$}

This sample is characterized by the presence of numerous volcanic glass shards with a wide variety of shapes that vary from simple to complex. Some are embedded in a sulphide-free, very fine-grained matrix of uncertain composition, while others occur in a matrix that is essentially a mosaic of sulphide masses. The masses are commonly angular, but exhibit a wide variety of shapes (Figure 1). It is possible that these shapes are in part due to the development of syneresis cracks in a sulphide gel during its conversion to pyrite. However, some appear to have resulted from the fracture of pyrite cubes during compaction.
Some of the glass fragments within the pyrite mosaic show no sign of sulphide replacement. In other fragments, replacement, varying from slight to virtually complete, has occurred (Figures 2 and 3 ). No consistent replacement pattern is seen, but the areas of preferred initial replacement may have been determined by local variations in the glass composition. Replacement is affected by the development of myriads of extremely small crystals that occasionally display a degree of ordering, are collectively browner in color and are more readily tarnished than the pyrite of the matrix in which the glass is embedded. The minute crystals are too small to be identified with certainty with the reflecting microscope but they possess a number of the characteristics of melnikovite-pyrite. However, collectively they lack the obvious colloform texture that this variety of pyrite usually displays (Ramdohr, 1969, pp. 793-797). Nevertheless, the fact that the crystals are commonly arranged in parallel bands may indicate that an original colloform texture was present (Figure 3).

Glass fragments that have resisted sulphide replacement, together with those that have suffered partial or complete replacement, are, when in a pyrite matrix, commonly seen to possess fractures filled with pyrite. The majority of these fractures tend to be approximately normal to the long axes of the shards (Figure 2). They 


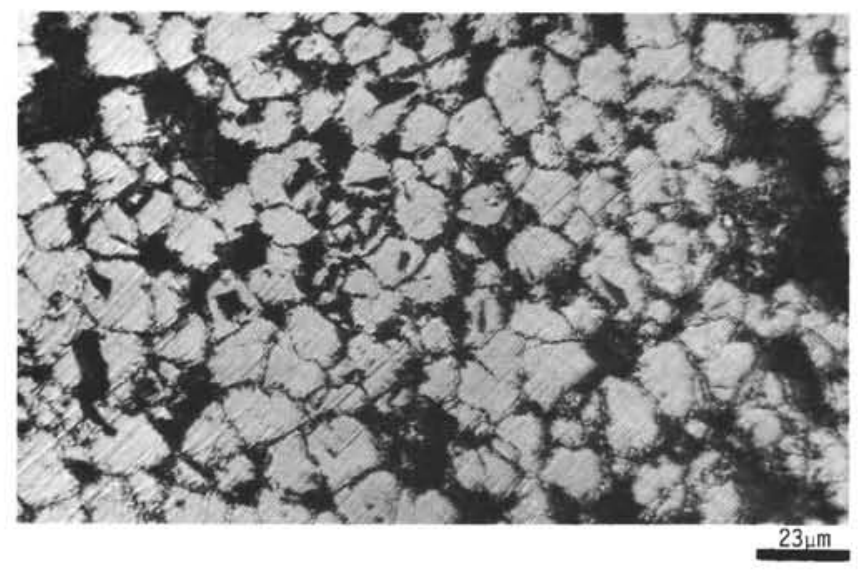

Figure 1. A photomicrograph of a portion of a polished section of Sample 1 showing the textural features of the pyrite mosaic in which glass shards are locally found. The texture may be in part due to syneresis cracks and is also surely in part the result of fracture of the pyrite during compaction.

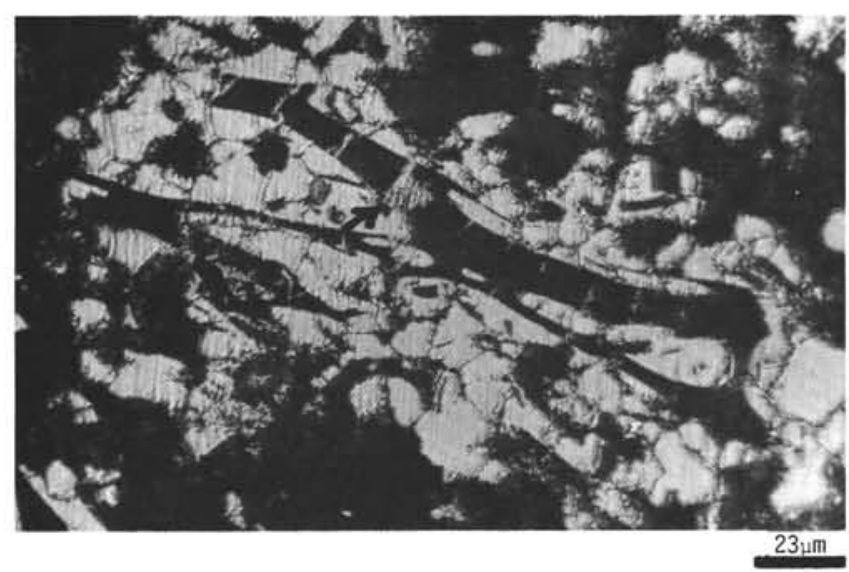

Figure 2. A photomicrograph of a portion of a polished section of Sample 1 in which elongate glass shards (black) occur that are characterized by transverse pyrite-filled fractures. These shards have suffered little replacement by sulphide, however, the largest one has been locally replaced by small well-ordered sulphide crystals. This replacement site is indicated by an arrow. The shards occur in a pyrite matrix.

probably owe their origin to tension generated when the sulphide gel in which they were embedded was converting to crystalline pyrite. Once the fractures had opened, it is probable that they were invaded by sulphide gel that further widened the fracture by the force of crystallization. This pull-apart/push-apart theory has been advocated earlier (Hosking, 1972; Hosking and Yeap, 1973) to account for the development of similar filled fractures in grains of quartz, in marcasite and siderite spherulites in the stanniferous placers of Southeast Asia, and for the disintegration of pyrite framboids in these spherulites.

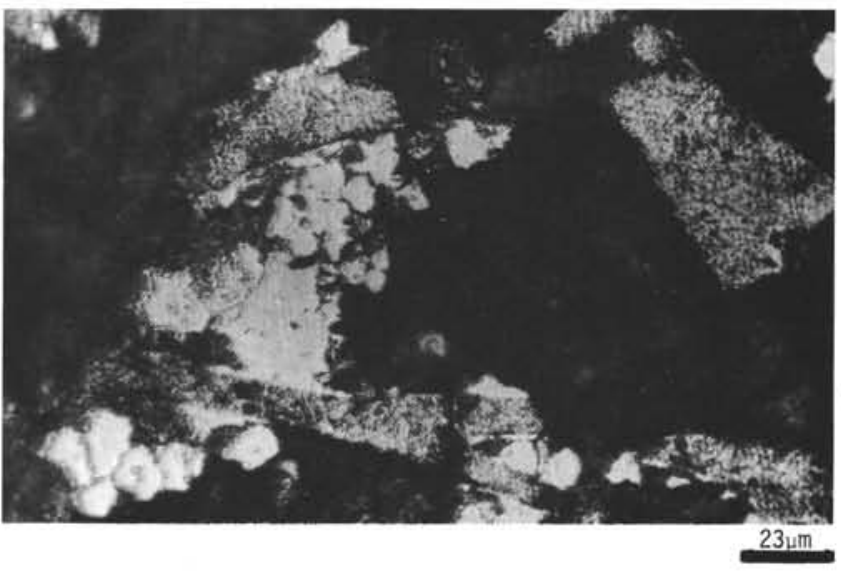

Figure 3. A photomicrograph of a portion of a polished section of Sample 1 showing glass shards that have been strongly replaced by minute sulphide crystals that show considerable ordering. This ordering might reflect an earlier colloform texture.

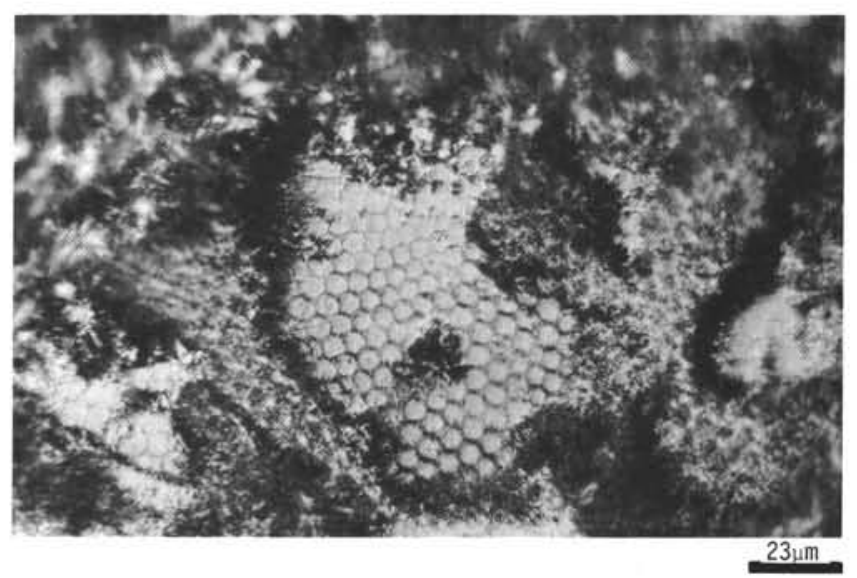

Figure 4. A photomicrograph of a portion of a polished section of Sample 2 showing the beautiful honeycomb texture of a fragment of a pyritized microorganism (Radiolaria ?). (Oil immersion.)

Finally it is relevant to note that the replacement of the glass by sulphide may be found in areas lacking pyrite in the matrix. Thus, this replacement is independent of the development of the matrix pyrite and is an earlier event.

\section{Sample 2 (31-297-4-3, 80-81 cm)}

This sample is of interest because within its pyrite matrix are a number of interesting pyritized inclusions. Two of these are small, irregularly shaped plates that are characterized by a honeycomb texture in which each cell is $\sim 2 \mu$ across (Figure 4). T. E. Yancey (personal communication), suggests that perhaps these are portions of pyritized Radiolaria.

In addition, a number of small inclusions, some of which are circular in section, are seen locally. These con- 


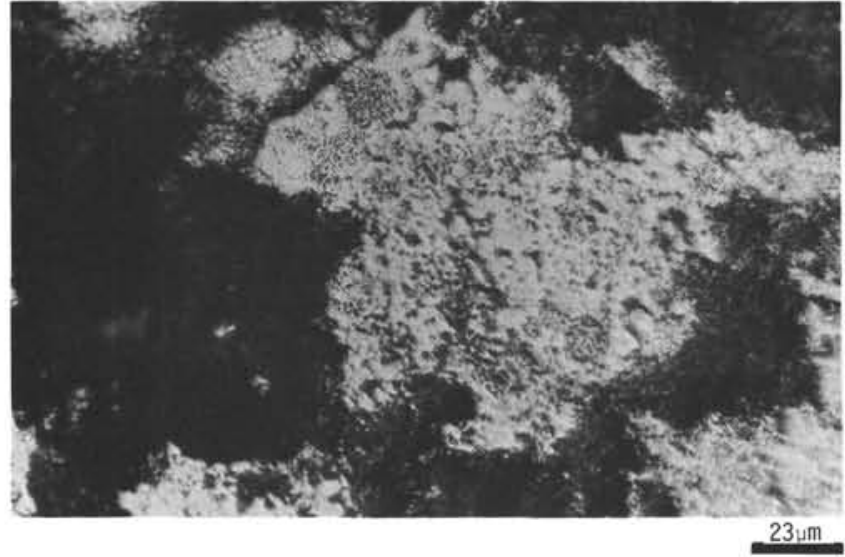

Figure 5. A photomicrograph of a portion of a polished section of Sample 2 showing inclusions in a pyrite matrix. The inclusions, some of which are crudely circular, consist of aggregates of minute, often quite well-ordered pyrite crystals. The inclusions are thought to be pyritized microorganisms, perhaps, in part, Radiolaria.

sist of minute pyrite crystals which may show a certain amount of ordering (Figure 5). Initially it was thought that some might be partially obliterated framboids and others, disrupted ones. The writer now believes that no framboids are present, and that the various inclusions in question are the pyritized tests of microorganisms, possibly Radiolaria.

\section{FURTHER SULPHIDE MATERIAL}

As noted earlier, two other samples of sulphide material previously sealed in cells on microscope slides were superficially examined. Sample $31-298-2$, CC consisted of four 'cylinders', each about $270 \mu$ in diameter, and a length varying between $1696 \mu$ and $2720 \mu$. One possessed a relatively thin wall; another was reminiscent of a piece of worm-eaten wood that had been pyritized. Undoubtedly these are portions of organisms that have been replaced by sulphides. It is possible they are parts of sea urchin spines.

Sample 31-298-3, CC consists of a number of sulphide spherulites, or portions thereof, whose diameters are between $\sim 190 \mu$ and $\sim 820 \mu$. One partial sphere has a hollow center, and they all show a crude radial texture.

\section{GENESIS OF THE PYRITE}

The sulphides under review were developed locally at or close to the surface of the ocean floor where euxinic conditions prevailed. Precisely how pyrite and related iron sulphides are developed in marine sediments is still open to question. The various views on the subject are well summarized by Roberts (1968). It is, however, generally agreed that the hydrogen sulphide $\left(\mathrm{H}_{2} \mathrm{~S}\right)$ necessary for the syntheses may be largely the product of reduction of sulphate ions of the seawater by bacteria, while the iron may be derived from hydrated iron oxide. If, as Berner and others believe (Berner, 1969), the pyrite of marine sediments develops from the reaction between elemental sulphur and originally precipitated black ferrous sulphide (i.e., $\mathrm{S}+\mathrm{FeS} \rightarrow \mathrm{FeS}_{2}$ ) then this sulphur is also, in all probability, derived from $\mathrm{H}_{2} \mathrm{~S}$ by a further biogenic process.

Conversely, because the samples were collected near a region of active volcanoes, it is possible that some or all of the components required for the formation of the pyrite originated in the underlying bedrock, at an unknown depth, and subsequently migrated to the depositional site.

For the material studied, two generations of sulphide can be ascertained. The earlier was restricted to the local replacement of glass fragments by pyrite melnikovite(?) and to the replacement of fragments of microorganisms by normal pyrite. The later generation is represented by pyrite investing the glass fragments and microorganisms, and filling fractures in the replaced glass fragments.

Possibly both generations of pyrite passed through a gel state; some slight evidence of this in the first generation has been provided. Additionally, it has been suggested that the texture of the second generation pyrite may be in part due to syneresis cracks; however, it is not possible to say with certainty that such cracks exist.

\section{ACKNOWLEDGMENTS}

The writer is grateful to N. S. Haile, Department of Geology, University of Malaya, for kindly providing him with the material for study, and to Cik Zohara Bee Samsudin for assisting in the preparation of the photomicrographs.

\section{REFERENCES}

Berner, R. A., 1969. The synthesis of framboidal pyrite: Econ. Geol., v. 64, p. 383-384.

Hosking, K. F. G., 1972. Siderite spherulites from Ayer Hitam, Selangor: Geol. Soc. Malaysia Newslett., no. 35, p. $1-5$.

Hosking, K. F. G. and Yeap, E. B., 1973. Marcasite spherulites from the Ban Seng Lee Mine, near Tronoh, Perak: Geol. Soc. Malaysia Newslett. no. 43, p. 1-4.

Ramdohr, P., 1969. The ore minerals and their intergrowths: Oxford (Pergamon Press).

Roberts, W. M. B., 1968. The formation of pyrite from hydrated iron oxide in aqueous solution at $20^{\circ} \mathrm{C}$ : Mineral. Depos. (Berlin), v. 3, p. 364-367. 